\title{
A factorial study on human resource issues of small and medium enterprises
}

\author{
Mohamed Mohiya ${ }^{a}$, Shaha Faisal ${ }^{a *}$ and M.M. Sulphey ${ }^{b}$
}

${ }^{a}$ Assistant professor, Department of HRM, College of Business Administration, Prince Sattam Bin Abdulaziz University, Al Kharj, Saudi Arabia

${ }^{b}$ Professor, Department of HRM, College of Business Administration, Prince Sattam Bin Abdulaziz University, Al Kharj, Saudi Arabia

\section{CH R O N I C L E}

Article history:

Received: December 28, 2019

Received in revised format:

January 302020

Accepted: February 19, 2020

Available online:

February 19, 2020

Keywords:

Small Medium Enterprise

SME

Employer

Employee

Human Resource issues

\section{A B S T R A C T}

Small Medium Enterprises (SMEs) play a vital role for the development of any economy. Multiple studies with respect to various aspects and dimensions of SMEs have been undertaken. Some of the problems faced by SMEs from the side of the employees include performance management issues, employee issues like strikes, go slow tactics, and so on. However, studies that explore the issues as perceived by employers are scarce. The present research is undertaken to find out the various human resource issues as perceived by employers. Data for the present study was collected from 60 SMEs. The organizations belonged to various sectors. Factor Analysis was performed to identify the factors. The analysis identified two factors as perceived by employers regarding human resource issues in SMEs. The reliability and validity of the factors were also assessed, which was found to be sufficiently high. A few suggestions for further research are also presented.

C 2020 by the authors; licensee Growing Science, Canada

\section{Introduction}

Since Small Medium Enterprises (SMEs) play a vital role for the development of any nation, it is accorded prime importance. This sector presents a strong edifice on which national development is based - through focusing on employment generation, production, research and innovation, and so on. Recent figures show that the sector contributed around $28.7 \%$ of gross domestic product (GDP), 31.83\% of India's total manufacturing output and employment to approx. 1,10.99 million (Annual Report of Ministry of MSME, 2018-2019). MSMEs are also considered as vehicles of economic growth, as it has the capability to contribute substantially towards productivity, completeness and employment generation. Over and above these, this sector has a social dimension as it provides career opportunities, training and empowerment weaker section of the society (Faisal \& Sulphey, 2018a; Hussain et al., 2012). However, SMEs have many issues and problems which are unique to them. One of the major issues is sustainability (Sulphey \& Al Kahtani, 2017). For instance, SMEs find it difficult to retain talents as they cannot afford to match the pay and benefits offered by large industries and compete with them. SMEs also find it difficult to deal with performance management issues, and cope with other employee demands and different industrial actions like strikes, go slow tactics, etc. (Chaudhary \& Singh 2014; Singh et al., 2017). Though many studies have been undertaken in this regard in large industries, only very few have been performed in SEMs (Cassell et al., 2002; Cardon \& Stevens, 2004; Hornsby \& Kuratko, 2003; Madhani, 2012). The focus of this work is thus on the human resource (HR) issues faced by SMEs. The present study intends to fill this gap in literature by focusing on the HR issues faced by MSMEs. 


\subsection{Review of literature}

The fact that effective HRM practices act as a key drivers of SME performance and are essential for their survival have been largely ignored (Chaudhary \& Singh, 2014; Rajeevan \& Sulphey, 2012; Rajeevan et al., 2015). Many studies have pointed towards the direction that effective HRM is one of the challenges faced by SME's. However, only few empirical studies have examined this important aspect (Chandler \& Mcevoy, 2000). This is because most SMEs maintains priority in facing competitions. This in turn results in the neglect of people management and other HRM related issues (Matlay, 1999; Madhani, 2012; Sulphey, 2015). However, Pandey and Chauhan (2014) found that majority of SMEs to receive assistance from HR outsources, and do away with hiring permanent staff. Literature exists to suggest that SMEs adopt their own individualistic approach for employment relations (McDonald, 2005; Thiruchanuru, 2016; Wilkinson, 1999). The problems faced by SMEs are multitude and varied. A few of them include problems associated with recruitment and selection, labor turnover, conflicts, lack of managerial talent, etc. (Agwu \& Emeti, 2014; Mallett \& Wapshott 2017; Samuel, 2018; Singh et al., 2017; Thiruchanuru, 2016). Labor turnover has been found to be one of the major concerns for SME's by Thiruchanuru (2016). It is common practice for SME employees after acquiring the required skills and thereafter leave the organization. The main reason for the financial constraints is faced by most of the SMEs (Faisal \& Sulphey, 2018 b). Thiruchanuru (2016) identified "Scarcity of Technical Skills" and "non-availability of skilled labor" as the factors faced by most SMEs. This is despite the fact that there is a continued demand of skilled labor. Another aspect that is critical to SMEs is keeping themselves abreast of the labor laws and the multitude of statutory requirement (Faisal \& Ilyas, 2016).

Employer-employee conflict is another compelling problem faced by SMEs, which has a negative effect on the performance (Samuel, 2018). The study by Samuel (2018) highlighted a few sources of the conflict. Some of them include work overload, salary dissatisfaction, poor communication, performance appraisal, work interruption and slow promotion. Due to conflicts employees react negatively which results in higher levels of wastages, absenteeism, sabotage, resignations and hostilities. Another major hurdle faced by the sector is associated with the availability of skilled manpower (Agwu \& Emeti, 2014; Lahiri, 2012; Thiruchanuru, 2016). Limited financial resources constrain them from hiring professional talents, and the younger generations prefer big brands and names to SMEs. This results in big skill gap and limited choices for SMEs. In most organizations the technical skill gap is addressed by the owner, which could also pose other issues, as most of them could lack formal management and planning skills. Yet another issue faced is the informal way of recruitment and selection practiced by SMEs (Singh et al., 2017). These hiring practices could result in the organization being saddled with the liability of having HR that may not bring in value addition, and hence results to loss of revenue. Conversely, fewer recourses at the disposal of SMEs also impedes them from offering wages and benefits (Deveau, 2018). Compensation, benefits, advancement in career, etc. are other aspects that act as impediments for SMEs that prevent them from attracting new entrants (Mallett \& Wapshott, 2017). Employment relationship is affected by nature of firm and also influenced by the environment where these firms are operating. Based on the review of literature, the following objectives were identified for the study is to identify factors as perceived by employers about HR issues faced by SMEs

\section{Material and methods}

A fair review revealed that most of the previous studies focused mostly on employee related issues like compensation, training and development, performance appraisal, welfare of employees, quality of work life, etc. Due to this, a paucity of scale to assess the issues faced by employers was found. The present researchers thus took up the challenge of constructing a scale which can measure issues faced by employers in SMEs. This study followed the method proposed by Kumar and Beyerlein (1991) with respect to all aspects of tool construction like creation of item pool, item selection, item reduction, reliability and validity, etc. Factor Analysis (FA) was used to meet the objectives of the study.

\subsection{Item construction}

The required number of items was decided with great care as it is very important and it can affect the respondent's response directly as this crucial stage of scale development (Hinkin, 1995, Samsuddin \& Sulphey, 2017). Content validity is also very important in order to measure the items adequacy and this is first step also in new construct development. According to Hinkin (1995) the items should cover theoretical domains and capable of measuring them. The three domains were identified Employee's behavior, Employees loyalty, Employee commitment and performance. These are important to cover up the content as well as construct validity (Cronbach \& Meehi 1955). All items of the pool were checked thoroughly and those which were found similar omitted. After the screening process 15 items were finalized. Aall these items were found to be appropriate to measure the employer issues of SME's. After this process these items were reviewed by four expert of industry and academia. 


\subsection{Item selection}

In this stage the items of the construct which provides appropriate and accurate account of the construct to be investigated was identified. 15 items were thus identified. It was decided to have a 5-point Likert scale that ranged from ('strongly agree' to 'strongly disagree). Hinkin (1995) explained that to get the appropriate result the proper length of scale is required. The questionnaire prepared was administered directly on the employers of different SMEs, having varying demographics, in the state of Uttar Pradesh, India. Great care was taken while administering the questionnaire so that the sample is representative in nature. Data for the study was collected from 60 sample units, which belonged to various types of SMEs. Majority of SMEs in the sample study employed over 30 employees and had capital investment ranging between INR 50 lakhs to two crores. Majority of units in the sample were private limited companies (60\%), public limited companies (20\%), partnership firm (13.33\%) respectively and the rest were proprietorship firms (6.67\%).

\subsection{Item Reduction}

In order to minimize the skewness and maximize variance, the items having larger means and variances have been retained with the construct. In the present study the mean score of items (ranges from 2.73 to 3.63) and contains larger variances as well. All items inter item correlation score is more than .7, therefore, no items can be removed. Thereafter, the item-to total correlations was analyzed. It was observed that for all items the $r$ value was more than .40 , so no items need to be eliminated (Kim \& Mueller, 1978). This clearly specifies that all items of the questionnaire represent from the same domain. Chruchill (1979) revealed that if the inter-correlations score is low it indicates that items have not been selected from the suitable domain and result will not be appropriate and lead to unreliability as well. In present case the minimum item to total correlation score was 6.33 and the maximum was 8.33. As per Kim and Mueller (1978) those items can be retained for which co-relation score is more than .40 . Since all 15 items were having score more then .40 , they were retained. Table 1 presents the mean, standard deviation and item-to-total correlations.

Table 1

Result of Mean, SD and Item-to-total correlations

\begin{tabular}{cccc}
\hline Item No. & Mean & SD & R \\
\hline 1. & 2.73 & 1.29 & 0.820 \\
2. & 2.90 & 1.47 & 0.837 \\
3. & 3.52 & 1.49 & 0.748 \\
4. & 3.22 & 1.54 & 0.868 \\
5. & 2.97 & 1.46 & 0.855 \\
6. & 2.93 & 1.48 & 0.880 \\
7. & 2.98 & 1.49 & 0.798 \\
8. & 2.95 & 1.47 & 0.866 \\
9. & 2.77 & 1.36 & 0.818 \\
10. & 2.58 & 1.48 & 0.756 \\
11. & 2.87 & 1.48 & 0.875 \\
12. & 2.93 & 1.49 & 0.853 \\
13. & 3.63 & 1.37 & 0.725 \\
14. & 3.07 & 1.35 & 0.730 \\
15. & 2.87 & 1.48 & 0.871 \\
\hline
\end{tabular}

Thereafter, Exploratory Factor Analysis (EFA) was done.

\section{Results}

\subsection{Factor Analysis}

FA can help in data reduction and refining of constructs (Kerlinger et al., 1986). The EFA was performed with principal component method and oblique factor rotation, for meeting the objectives of the study. The purpose of FA is to discard the unrelated items and to obtain meaningful dimension as per Hair et al. (1987). The items are factored again and forced into a specified number of factors. That solution is then rotated. This is called factor rotation. This FA extracted two factors with Eigen Values of 10.129 and 1.190 respectively. The details are presented in Table 2. Factor 1 had eight items and was designated as "Attitudinal Issues" while Factor 2 is loaded with seven related items therefore designated as "Relational Issues". These two factors variance score was $75.46 \%$, the first factor variance obtained $67.53 \%$ score while second factor had accounted $7.93 \%$. Results are shown in Table 2 . 
Table 2

Factor Analysis of Employer questionnaire

\begin{tabular}{|c|c|c|c|}
\hline No. & Items & Attitudinal Issues & Relational Issues \\
\hline 1. & Absence of ethical behavior from employees side. & 0.866 & \\
\hline 2. & Employees share company's confidential information to outsiders & 0.852 & \\
\hline 3. & Unawareness about performance and productivity. & 0.828 & \\
\hline 4. & Employees avoids the supervisor instructions & 0.816 & \\
\hline 5. & They do not try to work efficiently & 0.804 & \\
\hline 6. & Employees always resist proactive change. & 0.779 & \\
\hline 7. & Lack of loyalty and commitment towards organizational objectives. & 0.763 & \\
\hline 8. & Ambition of labor for higher wages and bonus. & 0.587 & \\
\hline 9. & The union leaders play politics for their own benefits & & 0.876 \\
\hline 10. & Employees do not follow the rules and the regulations & & 0.826 \\
\hline 11. & Strikes as result of punishment for gross indiscipline & & 0.814 \\
\hline 12. & Employees go slow tactics & & 0.779 \\
\hline 13. & Employees more often bring unreasonable demands. & & 0.709 \\
\hline 14. & Employees misleads other colleagues & & 0.665 \\
\hline \multirow[t]{7}{*}{15.} & I do not like the interference of outsiders who insight the trade unions & & 0.521 \\
\hline & Eigen Values & 10.129 & 1.190 \\
\hline & Percent of variance explained & 67.529 & 7.933 \\
\hline & Cumulative percent of variance explained & 67.529 & 75.462 \\
\hline & Mean & 24.017 & 20.90 \\
\hline & Standard Deviation & 10.38 & 8.33 \\
\hline & Alpha & .957 & .933 \\
\hline
\end{tabular}

Inter-factor correlation: A positive correlation was found between the two factors $(\mathrm{r}=.809)$, which is significant at 0.01 level.

\subsection{Reliability and validity}

Reliability refers to correctness of a measuring instrument which is necessary for the validity (Kerlinger, 1986). The reliability of the questionnaire was assessed through internal consistency method and the two factors were found to be of conceptually related dimensions, as proposed by Spector (1992). The Cronbach's Alpha of Factor 1 was found to be .957 and Factor 2.933 respectively. This value is above .70 as standard set by Nunnally (1978). High value of alpha denotes that all items of the questionnaire are consistent in nature (Kumar \& Beyerlein, 1991). Validity of a questionnaire could be content, criterion and construct. Content validity of a scale means that items of particular scale are capable of measuring what intended and give full coverage of the content (Kumar \& Beyerlein 1991). The construct and all items were developed after thoroughly reviewing the literature. The expert opinion was also taken and items were reviewed by them to validate the construct (Schultz \& Whitney, 2005). Construct validity is related with the appropriateness of the attributes (Hinkin, 1995). Internal consistency denotes similarity of the different items of the questionnaire and measures the correlations of different items on the same test. Towards this the correlation of all the items were calculated. All the correlations were found to be significant at 0.01 level. This clearly denotes that this scale has higher internal consistency. A construct is accepted to have validity only when it measures what exactly it is intended to measure (Cronbach \& Meehi 1955). The construct is valid only if the items of particular construct conceptually and operationally well supported by theory (DeVon et al., 2007). There are many methods for the construct validity but FA was used in the present study. The analysis shows that the tool enjoys construct validity. The FA has also helped in identifying the factors that lead to HR issues, as perceived by employers. The two factors thus identified are "Attitudal Issues" and "Relational Issues".

\section{Discussion}

SMEs throughout the world are accepted as a foundation of economic development for developing nation like India. The present study was undertaken to identify the problem as perceived by employers, which are responsible for poor employeremployee relations that hamper the growth potential of the SME sector. FA was done to identify the factors that could lead to HR issues in SMEs. The study has succeeded in identifying two factors "Attitudinal Issues" and "Relational Issues" on the employees end are the main HR issues faced by SMEs. The findings are similar to that of Samuel (2018) and Thiruchanuru (2016). There is a definite need for more studies, especially the HR issues faced by SMEs, as it is highly fecund area for researchers. It also has wide theoretical and practical implications including societal benefits. The authors expect that the present work would act as a trigger for further works in this area. 


\section{Conclusion}

SMEs have a plethora of issues that act as impediments to their functioning and hamper the relationship between employer and employees. The present study was undertaken with a limited sample. However, the results of the study are such that it can be generalized. There is further scope of a study with a larger sample with longitudinal data, spread over wider areas. A common issue identified by many studies are financial woes. Adequate funding to the SME's is one of the root causes of several problems of this sector. It also important to develop the essential infrastructure for SME's therefore basic requirement of this sector can be fulfilled. Employers need to implement sound organizational policy which must take care of interest of both organization and employees. Professional training is also required to avoid the delays and poor performance at work. The best employees must be rewarded for their professional work that will enhance the commitment level of the workforce. There is a need of sound communication system between employer and employees so middle man cannot play politics and insight the employees. Employers must design a reasonable pay structure, taking into due consideration their limitation, which includes monetary as well as non-monetary benefits for employees in order to compete with big organization.

\section{References}

Agwu, M. O., \& Emeti, C. I. (2014). Issues, challenges and prospects of small and medium scale enterprises (SMEs) in PortHarcourt city. European Journal of Sustainable Development, 3(1), 101-114.

Cardon, M. S., \& Stevens, C. E. (2004). Managing human resources in small organizations: What do we know?. Human Resource Management Review, 14(3), 295-323.

Cassell, C., Nadin, S., Gray, M., \& Clegg, C. (2002). Exploring human resource management practices in small and medium sized enterprises. Personnel Review, 31(6), 671-692.

Chandler, G.N. and McEvoy, G.M. (2000). Human Resource Management, TQM, and firm performance in small and mediumsize enterprizes. Enterpreneurship Theory and Practice, Fall, 43-57

Chaudhary, S., \& Singh, D. (2014). Can we relate organisational performance with HRM formality in organisations? International Journal of Commerce, Business and Management, 3, 514-518.

Cronbach, L. J., \& Meehl, P. C. (1955). Construct validity in psychological tests. Psychological Bulletin, 55, $281-302$.

DeVon, H. A., Block, M. E., Moyle-Wright, P., Ernst, D. M., Hayden, S. J., Lazzara, D. J., Savoy, S. M., \& Kostas-Polston E. (2007). A psychometric toolbox for 43 testing validity and reliability. Journal of Nursing Scholarship, 39(2), 155-164.

Faisal, S., \& Khan, I. (2016). Micro-small Enterprises: Emerging issues in India. International Journal of Business and Administration Review, 3(14)

Faisal, S., \& Sulphey M.M. (2018a). A study to identify the human resource problems as perceived by employees of small and medium enterprises sector in India. Journal of Advanced Research in Dynamical and control System, 10(special issue), $7-14$

Faisal, S., \& Sulphey M.M. (2018b). Crowdfunding as a potential avenue for mitigating Msme funding issues. International Journal of Research in Management, 6(1), 1-4.

Hair, J., Anderson, R. O., \& Tatham, R. (1987), Multidimensional data analysis,

Hinkin, T. R. (1995). A review of scale development practices in the study of organizations. Journal of Management, 21(5), 967-988.

Hornsby, J. S., \& Kuratko, D. F. (2003). Human resource management in U.S. How to Do it, Sage, Beverly Hills, CA.

Hussain, I., Farooq, Z., \& Akhtar, W. (2012). SMEs development and failure avoidance in developing countries through public private partnership. African Journal of Business Management, 6(4), 1581-1589.

Kerlinger, F. (1986). Foundations of Behavioral Research. $3^{\text {rd }}$ ed., Holt, Rinehart and Winston, New York.

Kim, J. O., Ahtola, O., Spector, P. E., \& Mueller, C. W. (1978). Introduction to factor analysis: What it is and how to do it (No. 13), Sage.

Kumar, K., \& Beyerlein, M. (1991). Construction and validation of an instrument for measuring ingratiatory behaviors in organizational settings. Journal of Applied Psychology, 76(5), 619-627.

Lahiri, R. (2012, October). Problems and prospects of micro, small and medium enterprises (MSMEs) in India in the era of globalization. In International Conference on the Interplay of Economics, Politics, and Society for Inclusive Growth, 1516. Macmillan, New York.

Madhani, P. (2012), Matching Compensation Strategies: Enhancing competitiveness. SCMS Journal of Indian Management, 9(1).

Mallett, O., \& Wapshott, R. (2017). Small business revivalism: employment relations in small and medium-sized enterprises. Work, Employment and Society, 31(4), 721-728.

Matlay, H. (1999). The paradox of training in the small business sector of the British economy. Journal of Vocational Education and Training, 49, 573-589.

McDonald, W.J.C. (2005). The ideology of managers in the management of employees in small andmedium sized enterprises in Australia (PhD Thesis). University of Southern Queensland, Toowoomba, Queensland.

Ministry of Micro, Small and Medium Enterprise (MSME), Annual Report (2018-19) https://msme.gov.in/sites/default/files/Annualrprt.pdf

Nunnally, J. C. (1978), Psychometric Theory, McGraw-Hill, New York. 
Pandey, T., \& Chauhan, A. S. (2014). HR issues towards managing MSMEs operating in India during globalization trends (with Special Reference to HR Outsourcing): An Extended Review. International Journal of Asian Business and Information Management (IJABIM), 5(3), 1-16.

Rajeevan, N., Sulphey M. M. \& Rajasekar S. (2015). The critical role of micro, small \& medium enterprises in employment generation: An Indian experience. Asian Social Science, 11(24), 258-267. http://doi:10.5539/ass.v11n24p258

Rajeevan, N. \& Sulphey, M.M. (2012). A study on the Position of small and medium enterprises in Kerala vis a vis the national scenario, International Journal of Research in Commerce, Economics \& Management, 2(3).

Samuel, R. (2018). Dimensionality of intra-organizational conflict and the challenges for human resource management in small and medium scale enterprises in nigeria. Journal of Competitiveness, 10(1), 125.

Schultz, K. S., \& Whitney, D. J. (2005). Measurement theory in action. Thousand Oaks.

Singh, R., Rigsby, J., \& Ramgulam, N. (2017). A study of small and Medium-Sized Enterprises (SMEs) in Trinidad: Formal human resource management practices and the performance of SMEs. Journal of Eastern Caribbean Studies, 42(2).

Spector, P. R. (1992). Summated Rating Scale Construction: An Introduction, 44 Quantitative Applications in the Social Sciences, 82, Sage University Papers Series, Newbury Park, CA.

Sulphey, M. M. \& Al Kahtani, N. S. (2017). Economic security and sustainability through social entrepreneurship: the current Saudi scenario. Journal of Security and Sustainability Issues, 6(3), 479-490. http://dx.doi.org/10.9770/jssi.2017.6.3(12)

Sulphey, M. M. (2015). Patterns of Employability Skills among Business Students. IPE Journal of Management, 5(2), July December.

Thiruchanuru, S. (2016). Strengthen the Small to Strengthen the Nation: Insights on HR Issues in SMEs. IUP Journal of Entrepreneurship Development, 13(2).

Wilkinson, A. (1999). Employment relations in SMEs. Employee Relations, 21(3), 206-217.

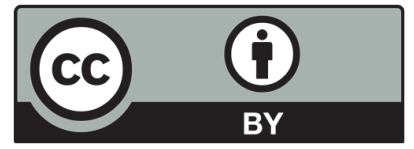

(C) 2020 by the authors; licensee Growing Science, Canada. This is an open access article distributed under the terms and conditions of the Creative Commons Attribution (CC-BY) license (http://creativecommons.org/licenses/by/4.0/). 